\title{
On Convergence of Fixed Points in Fuzzy Metric Spaces
}

\author{
Yonghong Shen, ${ }^{1,2}$ Dong Qiu, ${ }^{3}$ and Wei Chen ${ }^{4}$ \\ ${ }^{1}$ School of Mathematics and Statistics, Tianshui Normal University, Tianshui 741001, China \\ ${ }^{2}$ School of Mathematics, Beijing Institute of Technology, Beijing 100081, China \\ ${ }^{3}$ College of Mathematics and Physics, Chongqing University of Posts and Telecommunications, Chongqing 400065, China \\ ${ }^{4}$ School of Information, Capital University of Economics and Business, Beijing 100070, China
}

Correspondence should be addressed to Yonghong Shen; shenyonghong2008@hotmail.com

Received 7 November 2012; Accepted 9 July 2013

Academic Editor: Fasma Diele

Copyright (C) 2013 Yonghong Shen et al. This is an open access article distributed under the Creative Commons Attribution License, which permits unrestricted use, distribution, and reproduction in any medium, provided the original work is properly cited.

We mainly focus on the convergence of the sequence of fixed points for some different sequences of contraction mappings or fuzzy metrics in fuzzy metric spaces. Our results provide a novel research direction for fixed point theory in fuzzy metric spaces as well as a substantial extension of several important results from classical metric spaces.

\section{Introduction}

Fixed point theory of classical metric spaces plays an important role in general topology. In 1988, Grabiec [1] first extended fixed point theorems of Banach and Edelstein to fuzzy metric spaces in the sense of Kramosil and Michalek. Since then, many authors had dedicated themselves to the study of fixed point theory in fuzzy metric spaces [2-18]. Besides, some authors extended fixed point theory to other types of fuzzy metric spaces in recent years. For instance, Alaca et al. [19] extended the well-known fixed point theorems of Banach and Edelstein to intuitionistic fuzzy metric spaces with the help of Grabiec's work. Simultaneously, Mohamad [20] and Razani [21] proved the existence of fixed point for a nonexpansive mapping of intuitionistic fuzzy metric spaces and the intuitionistic Banach fixed point theorem in complete intuitionistic fuzzy metric spaces, respectively. Later, Ćirić et al. [22] investigated the existence of fixed points for a class of asymptotically nonexpansive mappings in an arbitrary intuitionistic fuzzy metric space. On the other hand, Adibi et al. [23] extended a common fixed point theorem to $L$ fuzzy metric spaces and proved a coincidence point theorem and a fixed point theorem for compatible mappings of type $(P)$ in these spaces. In 2008, Ješić and Babačev [24] further studied some common fixed point theorems for a pair of $R$-weakly commuting mappings with nonlinear contractive condition in intuitionistic fuzzy metric spaces and $L$-fuzzy metric spaces. In the same year, Park et al. [25] extended some common fixed point theorems for five mappings to $M$ fuzzy metric spaces. Up to now, one can see that the majority of papers mainly focus on the existence of fixed points for different mappings in different fuzzy metric spaces. However, the aim of this paper is to show that the convergence of the sequence of fixed points to some sequences of contraction mappings or fuzzy metrics satisfies certain conditions in fuzzy metric spaces.

\section{Preliminaries}

Now, we begin with some basic concepts and lemmas. Let $\mathbb{N}$ denote the set of all positive integers.

Definition 1 (Schweizer and Sklar [26]). A binary operation * : $[0,1] \times[0,1] \rightarrow[0,1]$ is called a continuous triangular norm (shortly, continuous $t$-norm) if it satisfies the following conditions:

$(\mathrm{TN}-1) *$ is commutative and associative;

$(\mathrm{TN}-2) *$ is continuous;

$(\mathrm{TN}-3) a * 1=a$ for every $a \in[0,1]$;

(TN-4) $a * b \leq c * d$ whenever $a \leq c, b \leq d$, and $a, b, c, d \in[0,1]$. 
In particular, a $t$-norm $*$ is said to be positive [27] if $a * b>$ 0 whenever $a, b \in(0,1]$.

We redefine the notion of a fuzzy metric space by appending the following condition (FM-6) based on the one in the sense of George and Veeramani [2].

Definition 2. A fuzzy metric space is an ordered triple ( $X$, $M, *)$ such that $X$ is a (nonempty) set, $*$ is a continuous $t$ norm, and $M$ is a fuzzy set on $X \times X \times(0, \infty)$ satisfying the following conditions, for all $x, y, z \in X, s, t>0$ :

$$
\begin{aligned}
& (\mathrm{FM}-1) M(x, y, t)>0 ; \\
& (\mathrm{FM}-2) M(x, y, t)=1 \text { if and only if } x=y ; \\
& (\mathrm{FM}-3) M(x, y, t)=M(y, x, t) ; \\
& (\mathrm{FM}-4) M(x, y, t) * M(y, z, s) \leq M(x, z, t+s) ; \\
& (\mathrm{FM}-5) M(x, y, \cdot):(0, \infty) \rightarrow(0,1] \text { is continuous; } \\
& (\mathrm{FM}-6) \lim _{t \rightarrow \infty} M(x, y, t)=1 .
\end{aligned}
$$

Definition 3 (Grabiec [1] and Vasuki and Veeramani [17]). Let $(X, M, *)$ be a fuzzy metric space. Then

(a) a sequence $\left\{x_{n}\right\}$ is said to converge to $x$ in $X$, denoted by $x_{n} \rightarrow x$, if and only if $\lim _{n \rightarrow \infty} M\left(x_{n}, x, t\right)=1$ for all $t>0$; that is, for each $r \in(0,1)$ and $t>0$, there exists an $n_{0} \in \mathbb{N}$ such that $M\left(x_{n}, x, t\right)>1-r$ for all $n \geq n_{0}$

(b) a sequence $\left\{x_{n}\right\}$ in $X$ is a G-Cauchy sequence if and only if $\lim _{n \rightarrow \infty} M\left(x_{n+p}, x_{n}, t\right)=1$ for any $p>0$ and $t>0$;

(c) the fuzzy metric space $(X, M, *)$ is called $G$-complete if every G-Cauchy sequence is convergent.

Definition 4 (Grabiec [1]). Let $(X, M, *)$ be a fuzzy metric space. A mapping $T: X \rightarrow X$ is called a contraction mapping if there exists $k \in(0,1)$ such that

$$
M(T x, T y, k t) \geq M(x, y, t)
$$

for every $x, y \in X$ and $t>0$.

According to fuzzy Banach contraction theorem of complete fuzzy metric space in the sense of Grabiec [1], we can obtain the following lemma.

Lemma 5. Let $(X, M, *)$ be a G-complete fuzzy metric space. If $T: X \rightarrow X$ is a contraction mapping, then $T$ has a unique fixed point.

Definition 6. Let $(X, M, *)$ be a fuzzy metric space and let $\left\{T_{n}\right\}$ be a sequence of self-mappings on $X . T_{0}: X \rightarrow X$ is a given mapping. The sequence $\left\{T_{n}\right\}$ is said to converge pointwise to $T_{0}$ if for each $r \in(0,1)$ and $x_{0} \in X$, there exists an $n_{0} \in \mathbb{N}$ such that

$$
M\left(T_{n} x_{0}, T_{0} x_{0}, t\right)>1-r
$$

for all $n \geq n_{0}$ and $t>0$.
Definition 7. Let $(X, M, *)$ be a fuzzy metric space and let $\left\{T_{n}\right\}$ be a sequence of self-mappings on $X . T_{0}: X \rightarrow X$ is a given mapping. The sequence $\left\{T_{n}\right\}$ is said to converge uniformly to $T_{0}$ if for each $r \in(0,1)$ and $t>0$, there exists an $n_{0} \in \mathbb{N}$ such that

$$
M\left(T_{n} x, T_{0} x, t\right)>1-r
$$

for all $n \geq n_{0}$ and $x \in X$.

Definition 8 . Let $(X, M, *)$ be a fuzzy metric space. A sequence of self-mappings $\left\{T_{n}\right\}$ is uniformly equicontinuous if for each $r \in(0,1)$, there exists an $\epsilon \in(0,1)$ such that $M(x, y, s)>1-\epsilon$ implies $M\left(T_{n} x, T_{n} y, t\right)>1-r$ for every $x, y \in X, n \in \mathbb{N}$, and $s, t>0$.

Definition 9 (George and Veeramani [2]). Let $(X, M, *)$ be a fuzzy metric space. The open ball $B(x, r, t)$ and closed ball $B[x, r, t]$ with center $x \in X$ and radius $r, 0<r<1, t>0$, respectively, are defined as follows:

$$
\begin{aligned}
& B(x, r, t)=\{y \in X: M(x, y, t)>1-r\}, \\
& B[x, r, t]=\{y \in X: M(x, y, t) \geq 1-r\} .
\end{aligned}
$$

Lemma 10 (George and Veeramani [2]). Every open (closed) ball is an open (a closed) set.

Definition 11 (Gregori and Romaguera [3]). A fuzzy metric space $(X, M, *)$ is a compact space if $\left(X, \tau_{M}\right)$ is a compact topological space, where $\tau_{M}$ is a topology induced by the fuzzy metric $M$.

Based on the corresponding conclusions stated in [2], we can easily obtain the following lemma.

Lemma 12. Every closed subset A of a compact fuzzy metric space $(X, M, *)$ is compact.

Lemma 13. Let $(X, M, *)$ be a fuzzy metric space and let $\left\{T_{n}\right\}$ be a sequence of self-mappings on $X . T_{0}: X \rightarrow X$ is a contraction mapping of $X$; that is, there exists $k \in(0,1)$ such that $M\left(T_{0} x, T_{0} y, k t\right) \geq M(x, y, t)$ for every $x, y \in X$. A is a compact subset of $X$. If $\left\{T_{n}\right\}$ converges pointwise to $T_{0}$ in $A$ and it is a uniformly equicontinuous sequence, then the sequence $\left\{T_{n}\right\}$ converges uniformly to $T_{0}$ in $A$.

Proof. For each $\bar{r} \in(0,1)$, we may choose an appropriate $r$ such that $(1-r) *(1-r) *(1-r)>1-\bar{r}$. Since $\left\{T_{n}\right\}$ is uniformly equicontinuous, there exists $\epsilon \in(0,1)(\epsilon \leq r)$ such that $M(x, y, s)>1-\epsilon \Rightarrow M\left(T_{n} x, T_{n} y, t\right)>1-r$ for every $x, y \in X, s, t>0$, and $n \in \mathbb{N}$. For the foregoing $\epsilon$, we fix $s>0$. Define $\mathscr{C}=\{B(x, \epsilon, s): x \in A\}$. By Lemma $10, \mathscr{C}$ is a family of open sets of $A$. Obviously, $\mathscr{C}$ constitutes an open covering of $A$; that is, $A \subset \bigcup B(x, \epsilon, s)$. Since $A$ is compact, there exist $x_{1}, x_{2}, \ldots, x_{m} \in A$ such that $A \subset \bigcup_{i=1}^{m} B\left(x_{i}, \epsilon, s\right)$. For every $x_{i} \in A(i=1,2, \ldots, m)$, since $\left\{T_{n}\right\}$ converges pointwise to $T_{0}$ in $A$, for $r \in(0,1)$, there exist $n_{i} \in \mathbb{N}(i=1,2, \ldots, m)$ such that $M\left(T_{n} x_{i}, T_{0} x_{i}, t\right)>1-r$ for all $n \geq n_{i}$. Set $n^{*}=\max \left\{n_{i}: i=\right.$ $1,2, \ldots, m\}$. Clearly, $n^{*}$ depends only on $r$. For every $x \in X$, there is an $i_{0} \in\{1,2, \ldots, m\}$ such that $x \in B\left(x_{i_{0}}, \epsilon, s\right)$. Then 
we have $M\left(x, x_{i_{0}}, s\right)>1-\epsilon \Rightarrow M\left(T_{n} x, T_{n} x_{i_{0}}, t\right)>1-r$ for all $n \in \mathbb{N}$. Thus, for all $n \geq n^{*}$,

$$
\begin{aligned}
& M\left(T_{n} x, T_{0} x,(2 t+k s)\right) \\
& \geq M\left(T_{n} x, T_{n} x_{i_{0}}, t\right) * M\left(T_{n} x_{i_{0}}, T_{0} x, t+k s\right) \\
& \geq M\left(T_{n} x, T_{n} x_{i_{0}}, t\right) * M\left(T_{n} x_{i_{0}}, T_{0} x_{i_{0}}, t\right) \\
& * M\left(T_{0} x_{i_{0}}, T_{0} x, k s\right) \\
& \geq M\left(T_{n} x, T_{n} x_{i_{0}}, t\right) * M\left(T_{n} x_{i_{0}}, T_{0} x_{i_{0}}, t\right) * M\left(x_{i_{0}}, x, s\right) \\
& \geq(1-r) *(1-r) *(1-\epsilon) \\
& \geq(1-r) *(1-r) *(1-r)>1-\bar{r} .
\end{aligned}
$$

Hence, the sequence $\left\{T_{n}\right\}$ converges uniformly to $T_{0}$ in $A$.

Definition 14. A fuzzy metric space $(X, M, *)$ in which every point has a compact neighborhood is called locally compact.

Definition 15. Let $\left(X, M_{0}, *\right)$ be a fuzzy metric space and let $\left\{M_{n}\right\}$ be a sequence of fuzzy metrics on $X$. The sequence $\left\{M_{n}\right\}$ is said to upper semiconverge uniformly to $M_{0}$ if for each $r \in$ $(0,1)$ and $t>0$, there exists an $n_{0} \in \mathbb{N}$ such that $M_{n}(x, y, t) \geq$ $M_{0}(x, y, t)$ and $M_{0}(x, y, t) / M_{n}(x, y, t)>1-r$ for all $n \geq n_{0}$, $x, y \in X$.

\section{Main Results}

Theorem 16. Let $(X, M, *)$ be a G-complete fuzzy metric space and let $\left\{T_{n}\right\}$ be a sequence of self-mappings on $X$ where t-norm $a * b=\min \{a, b\} . T_{0}$ is a contraction mapping of $X$; that is, there exists $k_{0} \in(0,1)$ such that $M\left(T_{0} x, T_{0} y, k_{0} t\right) \geq M(x, y, t)$ for all $x, y \in X, t>0$, and satisfying $T_{0} x_{0}=x_{0}$. If there exists at least a fixed point $x_{n}$ for each $T_{n}(n \in \mathbb{N})$ and the sequence $\left\{T_{n}\right\}$ converges uniformly to $T_{0}$, then $x_{n} \rightarrow x_{0}$.

Proof. Suppose that $x_{n} \nrightarrow x_{0}$; namely, there exist $t_{0}>0$ and $r_{0} \in(0,1)$ such that for any $n \in \mathbb{N}$ there is a $k(n)>n$ satisfying $M\left(x_{k(n)}, x_{0}, t_{0}\right)<1-r_{0}$. Fix a number $h \in\left(k_{0}, 1\right)$. According to the condition (FM-6) of Definition 2, for $t_{0}>0$, we can find an appropriate $p \in \mathbb{N}$ such that $M\left(x_{n}, x_{0}, t_{0}\left(h / k_{0}\right)^{p}\right)>$ $1-r_{0}$ for any $n \in \mathbb{N}$. Since the sequence $\left\{T_{n}\right\}$ converges uniformly to $T_{0}$, we can make $n_{0}$ sufficiently large such that $M\left(T_{n} x_{n}, T_{0} x, t\right)>1-r_{0}$ for all $n \geq n_{0}, t>0$. Now for $n \geq n_{0}$, we have

$$
\begin{aligned}
1-r_{0}> & M\left(x_{k(n)}, x_{0}, t_{0}\right) \\
= & M\left(T_{k(n)} x_{k(n)}, T_{0} x_{0}, t_{0}\right) \\
\geq & M\left(T_{k(n)} x_{k(n)}, T_{0} x_{k(n)},(1-h) t_{0}\right) \\
& * M\left(T_{0} x_{k(n)}, T_{0} x_{0}, h t_{0}\right) \\
\geq & M\left(T_{k(n)} x_{k(n)}, T_{0} x_{k(n)},(1-h) t_{0}\right) \\
& * M\left(x_{k(n)}, x_{0}, \frac{t_{0} h}{k_{0}}\right)
\end{aligned}
$$

$$
\begin{aligned}
\geq & M\left(T_{k(n)} x_{k(n)}, T_{0} x_{k(n)},(1-h) t_{0}\right) \\
& * M\left(T_{k(n)} x_{k(n)}, T_{0} x_{k(n)}, \frac{t_{0}(1-h) h}{k_{0}}\right) \\
& * M\left(x_{k(n)}, x_{0}, t_{0}\left(\frac{h}{k_{0}}\right)^{2}\right) \\
\geq & M\left(T_{k(n)} x_{k(n)}, T_{0} x_{k(n)},(1-h) t_{0}\right) \\
& * M\left(T_{k(n)} x_{k(n)}, T_{0} x_{k(n)}, \frac{t_{0}(1-h) h}{k_{0}}\right) \\
& * \cdots * M\left(T_{k(n)} x_{k(n)}, T_{0} x_{k(n)}, t_{0}(1-h)\left(\frac{h}{k_{0}}\right)^{p-1}\right) \\
& * M\left(x_{k(n)}, x_{0}, t_{0}\left(\frac{h}{k_{0}}\right)^{p}\right) \\
\geq & \underbrace{\left(1-r_{0}\right) *\left(1-r_{0}\right) * \cdots *\left(1-r_{0}\right)}_{p} *\left(1-r_{0}\right) \\
= & 1-r_{0} .
\end{aligned}
$$

This leads to a contradiction. Hence, $x_{n} \rightarrow x_{0}$.

Theorem 17. Let $(X, M, *)$ be a G-complete fuzzy metric space where $t$-norm is positive. If $T_{0}: X \rightarrow X$ is a self-mapping of $X$ and $T_{0}^{m}$ is a contraction mapping for a certain positive integer $m$, then $T_{0}$ has a unique fixed point.

Proof. First of all, if $m=1$, the theorem is evident. In addition, if $m \geq 2$, according to Lemma 5 , we need only to prove that $T_{0}$ is a contraction mapping. Since $T_{0}^{m}$ is a contraction mapping, there is $k_{0} \in(0,1)$ such that $M\left(T_{0}^{m} x, T_{0}^{m} y, k_{0}^{m} t\right) \geq$ $M(x, y, t)$ for every $x, y \in X$, and $t>0$. Define another fuzzy metric $\widetilde{M}(x, y, t)$ on $X$ using $M(x, y, t)$ as follows:

$$
\begin{aligned}
\widetilde{M} & (x, y, t) \\
= & M(x, y, t) * M\left(T_{0} x, T_{0} y, k t\right) \\
& * M\left(T_{0}^{2} x, T_{0}^{2} y, k^{2} t\right) * \cdots * M\left(T_{0}^{m-1} x, T_{0}^{m-1} y, k^{m-1} t\right) .
\end{aligned}
$$

Actually, it is easy to verify that the foregoing two fuzzy metrics are equivalent. Meantime, we claim that $T_{0}$ is a contraction mapping with respect to the fuzzy metric $\widetilde{M}(x, y, t)$, since

$$
\begin{aligned}
\widetilde{M} & \left(T_{0} x, T_{0} y, k_{0} t\right) \\
= & M\left(T_{0} x, T_{0} y, k t\right) * M\left(T_{0}^{2} x, T_{0}^{2} y, k^{2} t\right) \\
& * M\left(T_{0}^{3} x, T_{0}^{3} y, k^{3} t\right) * \cdots * M\left(T_{0}^{m} x, T_{0}^{m} y, k^{m} t\right) \\
\geq & M\left(T_{0} x, T_{0} y, k t\right) * M\left(T_{0}^{2} x, T_{0}^{2} y, k^{2} t\right) \\
& * M\left(T_{0}^{3} x, T_{0}^{3} y, k^{3} t\right) * \cdots * M(x, y, t)=\widetilde{M}(x, y, t) .
\end{aligned}
$$


Corollary 18. Let $(X, M, *)$ be a G-complete fuzzy metric space and let $\left\{T_{n}\right\}$ be a sequence of self-mappings on $X$ where $t$-norm $a * b=\min \{a, b\} . T_{0}: X \rightarrow X$ is a self-mapping of $X$, and $T_{0}^{m}$ is a contraction mapping for a certain positive integer $m$. If there exists at least a fixed point $x_{n}$ for each $T_{n}(n \in \mathbb{N})$ and the sequence $\left\{T_{n}\right\}$ converges uniformly to $T_{0}$, then $x_{n} \rightarrow x_{0}=T_{0} x_{0}$.

Proof. It follows from Theorems 16 and 17.

Theorem 19. Let $(X, M, *)$ be a locally compact fuzzy metric space and let $\left\{T_{n}\right\}$ be a sequence of self-mappings on $X . T_{0}$ : $X \rightarrow X$ is a contraction mapping; that is, there exists a $k_{0} \in$ $(0,1)$ such that $M\left(T_{0} x, T_{0} y, k_{0} t\right) \geq M(x, y, t)$ for all $x, y \in X$, $t>0$. If the following conditions are satisfied:

(i) $T_{n}^{m}$ is a contraction mapping for a certain $m=m(n)$,

(ii) $\left\{T_{n}\right\}$ converges pointwise to $T_{0}$ and $\left\{T_{n}\right\}$ is a uniformly equicontinuous sequence,

(iii) $T_{n} x_{n}=x_{n}, n=0,1,2,3, \ldots$,

then the sequence $\left\{x_{n}\right\}$ converges to $x_{0}$; that is, $x_{n} \rightarrow x_{0}$.

Proof. For each $\epsilon \in(0,1)$, we choose $r \in(0,1)$ such that $(1-r) *(1-r) \geq 1-\epsilon$. If given $x_{0} \in X$, we may assume that $r$ is sufficiently small such that $K\left(x_{0}, r\right)=\left\{x: M\left(x, x_{0}, t\right) \geq\right.$ $1-r\}$ is a compact subset of $X$. By Lemma 13, since $\left\{T_{n}\right\}$ is uniformly equicontinuous and pointwise convergent on $K\left(x_{0}, r\right)$, we know that $\left\{T_{n}\right\}$ converges uniformly to $T_{0}$ on the compact subset $K\left(x_{0}, r\right)$. Then, for the foregoing $r$, there exists $n_{\epsilon} \in \mathbb{N}$ such that $M\left(T_{n} x, T_{0} x,\left(1-k_{0}\right) t\right)>1-r$ for all $n \geq n_{\epsilon}, t>0$, and $x \in K\left(x_{0}, r\right)$. In addition, since $T_{0}$ is a contraction mapping, we have $M\left(T_{0} x, T_{0} y, k_{0} t\right) \geq M(x, y, t)$ for all $x, y \in K\left(x_{0}, r\right)$. Thus, for all $n \geq n_{\epsilon}$ and $x \in K\left(x_{0}, r\right)$, we can obtain

$$
\begin{aligned}
M\left(T_{n} x, x_{0}, t\right) & =M\left(T_{n} x, T_{0} x_{0}, t\right) \\
& \geq M\left(T_{n} x, T_{0} x,\left(1-k_{0}\right) t\right) * M\left(T_{0} x, T_{0} x_{0}, k_{0} t\right) \\
& \geq M\left(T_{n} x, T_{0} x,\left(1-k_{0}\right) t\right) * M\left(x, x_{0}, t\right) \\
& \geq(1-r) *(1-r) \geq 1-\epsilon .
\end{aligned}
$$

Therefore, for all $n \geq n_{\epsilon}, K\left(x_{0}, r\right)$ is an invariant set for $T_{n}$. Since $T_{n}^{m}$ is a contraction mapping for a certain positive integer $m=m(n)$, it follows that the fixed point $x_{n}$ of $T_{n}$ is contained in the set $K\left(x_{0}, r\right)$, when $n \geq n_{\epsilon}$. By the definition of $K\left(x_{0}, r\right)$, we have $M\left(x_{n}, x_{0}, t\right) \geq 1-r$ for all $n \geq n_{\epsilon}$. In fact, although $r$ should satisfy the foregoing condition, it may be sufficiently small. Hence, we can obtain $x_{n} \rightarrow x_{0}$.

In addition, if $t$-norm $a * b=a \cdot b$, then we can obtain the following some important conclusions.

Lemma 20. Let $\left(X, M_{0}, *\right)$ be a G-complete fuzzy metric space and let $A$ be a compact subset of $X$ where t-norm $a * b=a \cdot b$. $\left\{M_{n}\right\}$ and $\left\{T_{n}\right\}$ are a sequence of fuzzy metrics and a sequence of self-mappings on $X$, respectively. If they satisfy the following conditions:

(i) $\left\{M_{n}\right\}$ upper semiconverges uniformly to $M_{0}$,

(ii) $T_{n}$ is a contraction mapping for the fuzzy metric $M_{n}$, $n=0,1,2, \ldots$,

(iii) $\left\{T_{n}\right\}$ converges pointwise to $T_{0}$,

then $\left\{T_{n}\right\}$ converges uniformly to $T_{0}$ in $A$ with regard to the fuzzy metric $M_{0}$.

Proof. For each $\epsilon \in(0,1)$, choose $r \in(0,1)$ such that $(1-r) *$ $(1-r)>1-\epsilon$. Since $\left\{M_{n}\right\}$ upper semiconverges uniformly to $M_{0}$, there exists $n_{r} \in \mathbb{N}$ such that $M_{n}(x, y, t) \geq M_{0}(x, y, t)$ and $M_{0}(x, y, t) / M_{n}(x, y, t)>1-r$ for all $n \geq n_{r}, t>0$. Choose $x, y$ in $X$ such that $M_{0}(x, y, t)>1-r$ for each $t>0$. Then, for all $n \geq n_{r}$, we have

$$
\begin{aligned}
M_{0}\left(T_{n} x, T_{n} y, t\right) & =\frac{M_{0}\left(T_{n} x, T_{n} y, t\right)}{M_{n}\left(T_{n} x, T_{n} y, t\right)} * M_{n}\left(T_{n} x, T_{n} y, t\right) \\
& \geq(1-r) * M_{n}\left(T_{n} x, T_{n} y, t\right) \\
& \geq(1-r) * M_{n}\left(x, y, \frac{t}{k_{n}}\right) \quad\left(k_{n} \in(0,1)\right) \\
& \geq(1-r) * M_{0}\left(x, y, \frac{t}{k_{n}}\right) \\
& \geq(1-r) *(1-r)>1-\epsilon .
\end{aligned}
$$

Therefore, the sequence $\left\{T_{n}\right\}\left(n \geq n_{r}\right)$ is uniformly equicontinuous in $A$ with regard to the fuzzy metric $M_{0}$. Since $\left\{T_{n}\right\}$ is pointwise convergent and $A$ is a compact subset of $X$, according to Lemma 13, it follows that the subsequence $\left\{T_{n}\right\}\left(n \geq n_{r}\right)$ converges uniformly to $T_{0}$ in $A$. Hence, $\left\{T_{n}\right\}$ converges uniformly to $T_{0}$ in $A$.

Theorem 21. Let $\left(X, M_{0}, *\right)$ be a locally compact fuzzy metric space where t-norm $a * b=a \cdot b$. If $\left\{M_{n}\right\}$ and $\left\{T_{n}\right\}$ satisfy the following conditions:

(i) $\left\{M_{n}\right\}$ upper semiconverges uniformly to $M_{0}$,

(ii) $T_{n}$ is a contraction mapping for the fuzzy metric $M_{n}$, $n=0,1,2, \ldots$,

(iii) $\left\{T_{n}\right\}$ converges pointwise to $T_{0}$,

(iv) $T_{n} x_{n}=x_{n}, n=0,1,2, \ldots$,

then the sequence of fixed points $\left\{x_{n}\right\}$ of $\left\{T_{n}\right\}$ converges to the fixed point $x_{0}$ of $T_{0}$; that is, $x_{n} \rightarrow x_{0}$.

Proof. For each $\epsilon \in(0,1)$, choose $r \in(0,1)$ such that $(1-$ $r) *(1-r) \geq 1-\epsilon$. Meantime, for $x_{0} \in X$, we may make $r$ sufficiently small such that $K\left(x_{0}, r\right)=\left\{x: M\left(x, x_{0}, t\right) \geq 1-r\right\}$ is compact in $X$ for each $t>0$. By Lemma 20, we know that $\left\{T_{n}\right\}$ converges uniformly to $T_{0}$ in $K\left(x_{0}, r\right)$ with respect to the fuzzy metric $M_{0}$. Then, for every $x \in X$, there exists an $n_{r} \in \mathbb{N}$ 
such that $M_{0}\left(T_{n} x, T_{0} x, t\right)>1-r$ for all $n \geq n_{r}, t>0$. Thus, when $n \geq n_{r}$, for all $x \in K\left(x_{0}, r\right)$, we have

$$
\begin{aligned}
M_{0}\left(T_{n} x, x_{0},\left(1+k_{0}\right) t\right) \\
\quad \geq M_{0}\left(T_{n} x, T_{0} x, t\right) * M_{0}\left(T_{0} x, x_{0}, k_{0} t\right) \\
\quad \geq M_{0}\left(T_{n} x, T_{0} x, t\right) * M_{0}\left(T_{0} x, T_{0} x_{0}, k_{0} t\right) \\
\quad \geq M_{0}\left(T_{n} x, T_{0} x, t\right) * M_{0}\left(x, x_{0}, t\right) \\
\quad \geq(1-r) *(1-r) \geq 1-\epsilon .
\end{aligned}
$$

Therefore, $K\left(x_{0}, r\right)$ is an invariant set in $X$ with regard to $M_{0}$. Since $T_{n}$ is still a contraction mapping restricted to $K\left(x_{0}, r\right)$ concerning on $M_{n}$, one can see that the fixed point is also included in $K\left(x_{0}, r\right)$. Apparently, for all $n \geq n_{r}$, we can obtain $M\left(x_{n}, x_{0}, t\right) \geq 1-r$. Since $r$ is sufficiently small, it can easily be shown that $\left\{x_{n}\right\}$ converges to $x_{0}$; that is, $x_{n} \rightarrow x_{0}$. This completes the proof.

Theorem 22. Let $\left(X, M_{0}, *\right)$ be a compact fuzzy metric space where t-norm $a * b=a \cdot b$. The sequences $\left\{M_{n}\right\}$ and $\left\{T_{n}\right\}$ satisfy the following conditions:

(i) $\left\{M_{n}\right\}$ upper semiconverges uniformly to $M_{0}$;

(ii) $T_{n}$ is a contraction mapping for the fuzzy metric $M_{n}$, $n=0,1,2, \ldots$;

(iii) $\left\{T_{n}\right\}$ converges pointwise to $T_{0}$.

If every mapping $T_{n}(n \in \mathbb{N})$ has a fixed point $x_{n}$ and there is a subsequence $\left\{x_{n_{k}}\right\}$ of $\left\{x_{n}\right\}$ which converges to $x_{0}$, then $T_{0} x_{0}=$ $x_{0}$.

Proof. Let $K$ denote the closure of the set $\left\{x_{n_{k}}\right\}$. By Lemma 12, we can easily know that $K$ is a compact set. According to Lemma 20, it follows that the subsequence $\left\{T_{n_{k}}\right\}$ converges uniformly to $T_{0}$ in $K$ with regard to $M_{0}$. Obviously, $\left\{T_{n_{k}} x_{n_{k}}\right\}$ converges to $T_{0} x_{0}$. Hence, $T_{0} x_{0}=x_{0}$.

Theorem 23. Let $(X, M, *)$ be a fuzzy metric space. $\left\{T_{n}\right\}$ is a sequence of contraction mappings and satisfying $T_{n} x_{n}=x_{n}$ $(n=1,2,3, \ldots) . T_{0}: X \rightarrow X$ is a contraction mapping. If $\left\{T_{n}\right\}$ is a pointwise convergent sequence with respect to $T_{0}$ and the subsequence $\left\{x_{n_{k}}\right\}$ of $\left\{x_{n}\right\}$ converges to $x_{0}$, then $T_{0}$ has a fixed point $x_{0}=T_{0} x_{0}$

Proof. For each $\epsilon \in(0,1)$, choose $r \in(0,1)$ such that $(1-$ $r) *(1-r) \geq 1-\epsilon$. Since $\left\{x_{n_{k}}\right\}$ is a convergent subsequence and $\left\{T_{n}\right\}$ is a pointwise convergent sequence, for a given $x_{0}$, we may choose $K_{r} \in \mathbb{N}$ such that $M\left(x_{n_{k}}, x_{0}, t\right) \geq 1-r$ and $M\left(T_{n_{k}} x_{0}, T_{0} x_{0}, t\right) \geq 1-r$ for all $k \geq K_{r}, t>0$. For every $n \in$ $\mathbb{N} \cup\{0\}$, we denote by $l_{n}\left(l_{n} \in(0,1)\right)$ the contraction constant of $T_{n}$. Thus, for all $k \geq K_{r}$, we have

$$
\begin{aligned}
M\left(x_{n_{k}}, T_{0} x_{0},\left(l_{n_{k}}+1\right) t\right) \\
\quad=M\left(T_{n_{k}} x_{n_{k}}, T_{0} x_{0},\left(l_{n_{k}}+1\right) t\right) \quad l_{n_{k}} \in(0,1) \\
\quad \geq M\left(T_{n_{k}} x_{n_{k}}, T_{n_{k}} x_{0}, l_{n_{k}} t\right) * M\left(T_{n_{k}} x_{0}, T_{0} x_{0}, t\right) \\
\quad \geq M\left(x_{n_{k}}, x_{0}, t\right) * M\left(T_{n_{k}} x_{0}, T_{0} x_{0}, t\right) \\
\quad \geq(1-r) *(1-r) \geq 1-\epsilon .
\end{aligned}
$$

Therefore, the subsequence $\left\{x_{n_{k}}\right\}$ converges to $T_{0} x_{0}$. According to the uniqueness of limit, it follows that $x_{0}=T_{0} x_{0}$; that is, $x_{0}$ is a fixed point of $T_{0}$.

\section{Acknowledgments}

This work was supported by "Qing Lan” Talent Engineering Funds by Tianshui Normal University. Dong Qiu acknowledges the support of the National Natural Science Foundation of China (Grant no. 11201512) and the Natural Science Foundation Project of CQ CSTC (cstc2012jjA00001). Wei Chen acknowledges the support of the Beijing Municipal Education Commission Foundation of China (no. KM201210038001) and the Humanity and Social Science Youth Foundation of Ministry of Education of China (no. 13YJC630012).

\section{References}

[1] M. Grabiec, "Fixed points in fuzzy metric spaces," Fuzzy Sets and Systems, vol. 27, no. 3, pp. 385-389, 1988.

[2] A. George and P. Veeramani, "On some results in fuzzy metric spaces,” Fuzzy Sets and Systems, vol. 64, no. 3, pp. 395-399, 1994.

[3] V. Gregori and S. Romaguera, "Some properties of fuzzy metric spaces," Fuzzy Sets and Systems, vol. 115, no. 3, pp. 485-489, 2000.

[4] V. Gregori and A. Sapena, "On fixed-point theorems in fuzzy metric spaces," Fuzzy Sets and Systems, vol. 125, no. 2, pp. 245252, 2002.

[5] S. Kumar and D. Miheț, " $G$-completeness and $M$-completeness in fuzzy metric spaces: a note on a common fixed point theorem," Acta Mathematica Hungarica, vol. 126, no. 3, pp. 253$257,2010$.

[6] Y. Liu and Z. Li, "Coincidence point theorems in probabilistic and fuzzy metric spaces," Fuzzy Sets and Systems, vol. 158, no. 1, pp. 58-70, 2007.

[7] D. Miheţ, "A Banach contraction theorem in fuzzy metric spaces," Fuzzy Sets and Systems, vol. 144, no. 3, pp. 431-439, 2004.

[8] D. Miheț, "On fuzzy contractive mappings in fuzzy metric spaces," Fuzzy Sets and Systems, vol. 158, no. 8, pp. 915-921, 2007.

[9] D. Miheţ, "A class of contractions in fuzzy metric spaces," Fuzzy Sets and Systems, vol. 161, no. 8, pp. 1131-1137, 2010.

[10] D. Qiu and L. Shu, "Supremum metric on the space of fuzzy sets and common fixed point theorems for fuzzy mappings," Information Sciences, vol. 178, no. 18, pp. 3595-3604, 2008.

[11] D. Qiu, L. Shu, and J. Guan, "Common fixed point theorems for fuzzy mappings under $\Phi$-contraction condition," Chaos, Solitons \& Fractals, vol. 41, no. 1, pp. 360-367, 2009.

[12] S. Sedghi, I. Altun, and N. Shobe, "Coupled fixed point theorems for contractions in fuzzy metric spaces," Nonlinear Analysis: Theory, Methods \& Applications, vol. 72, no. 3-4, pp. 1298-1304, 2010.

[13] S. Sharma, "Common fixed point theorems in fuzzy metric spaces," Fuzzy Sets and Systems, vol. 127, no. 3, pp. 345-352, 2002.

[14] Y. H. Shen, D. Qiu, and W. Chen, "Fixed point theorems in fuzzy metric spaces," Applied Mathematics Letters, vol. 25, no. 2, pp. 138-141, 2012.

[15] Y. H. Shen, D. Qiu, and W. Chen, "Fixed point theory for cyclic $\varphi$-contractions in fuzzy metric spaces," Iranian Journal of Fuzzy Systems, vol. 10, pp. 125-133, 2013. 
[16] B. Singh and M. S. Chauhan, "Common fixed points of compatible maps in fuzzy metric spaces," Fuzzy Sets and Systems, vol. 115, no. 3, pp. 471-475, 2000.

[17] R. Vasuki and P. Veeramani, "Fixed point theorems and Cauchy sequences in fuzzy metric spaces," Fuzzy Sets and Systems, vol. 135, no. 3, pp. 415-417, 2003.

[18] G. Yun, S. Hwang, and J. Chang, "Fuzzy Lipschitz maps and fixed point theorems in fuzzy metric spaces," Fuzzy Sets and Systems, vol. 161, no. 8, pp. 1117-1130, 2010.

[19] C. Alaca, D. Turkoglu, and C. Yildiz, "Fixed points in intuitionistic fuzzy metric spaces," Chaos, Solitons \& Fractals, vol. 29, no. 5, pp. 1073-1078, 2006.

[20] A. Mohamad, "Fixed-point theorems in intuitionistic fuzzy metric spaces," Chaos, Solitons \& Fractals, vol. 34, no. 5, pp. 1689-1695, 2007.

[21] A. Razani, "Existence of fixed point for the nonexpansive mapping of intuitionistic fuzzy metric spaces," Chaos, Solitons \& Fractals, vol. 30, no. 2, pp. 367-373, 2006.

[22] L. B. Ćirić, S. N. Ješić, and J. S. Ume, “The existence theorems for fixed and periodic points of nonexpansive mappings in intuitionistic fuzzy metric spaces," Chaos, Solitons \& Fractals, vol. 37, no. 3, pp. 781-791, 2008.

[23] H. Adibi, Y. J. Cho, D. O’Regan, and R. Saadati, "Common fixed point theorems in L-fuzzy metric spaces," Applied Mathematics and Computation, vol. 182, no. 1, pp. 820-828, 2006.

[24] S. N. Ješić and N. A. Babačev, "Common fixed point theorems in intuitionistic fuzzy metric spaces and $L$-fuzzy metric spaces with nonlinear contractive condition," Chaos, Solitons \& Fractals, vol. 37, no. 3, pp. 675-687, 2008.

[25] J. H. Park, J. S. Park, and Y. C. Kwun, "Fixed points in M-fuzzy metric spaces," Fuzzy Optimization and Decision Making, vol. 7, no. 4, pp. 305-315, 2008.

[26] B. Schweizer and A. Sklar, "Statistical metric spaces," Pacific Journal of Mathematics, vol. 10, pp. 313-334, 1960.

[27] B. Schweizer and A. Sklar, Probabilistic Metric Spaces, NorthHolland Series in Probability and Applied Mathematics, NorthHolland Publishing, New York, NY, USA, 1983. 


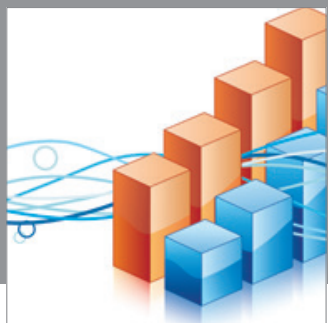

Advances in

Operations Research

mansans

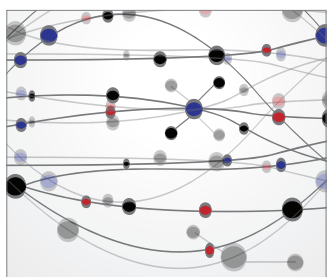

The Scientific World Journal
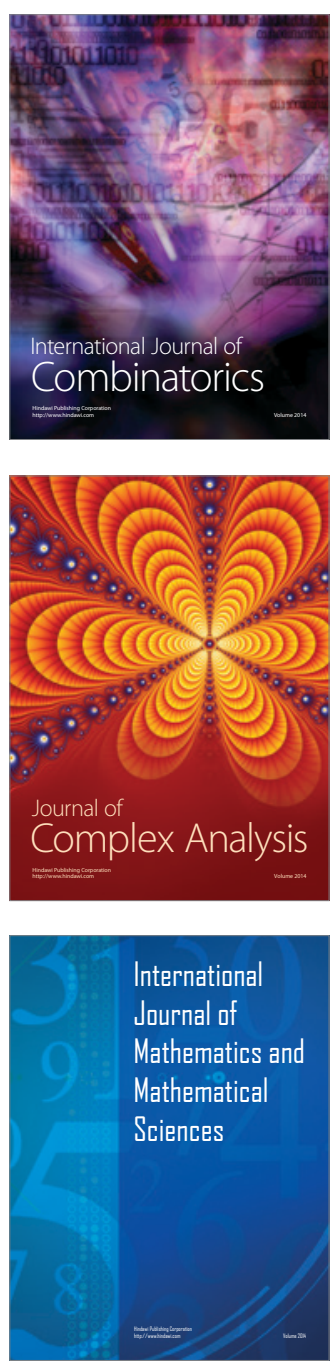
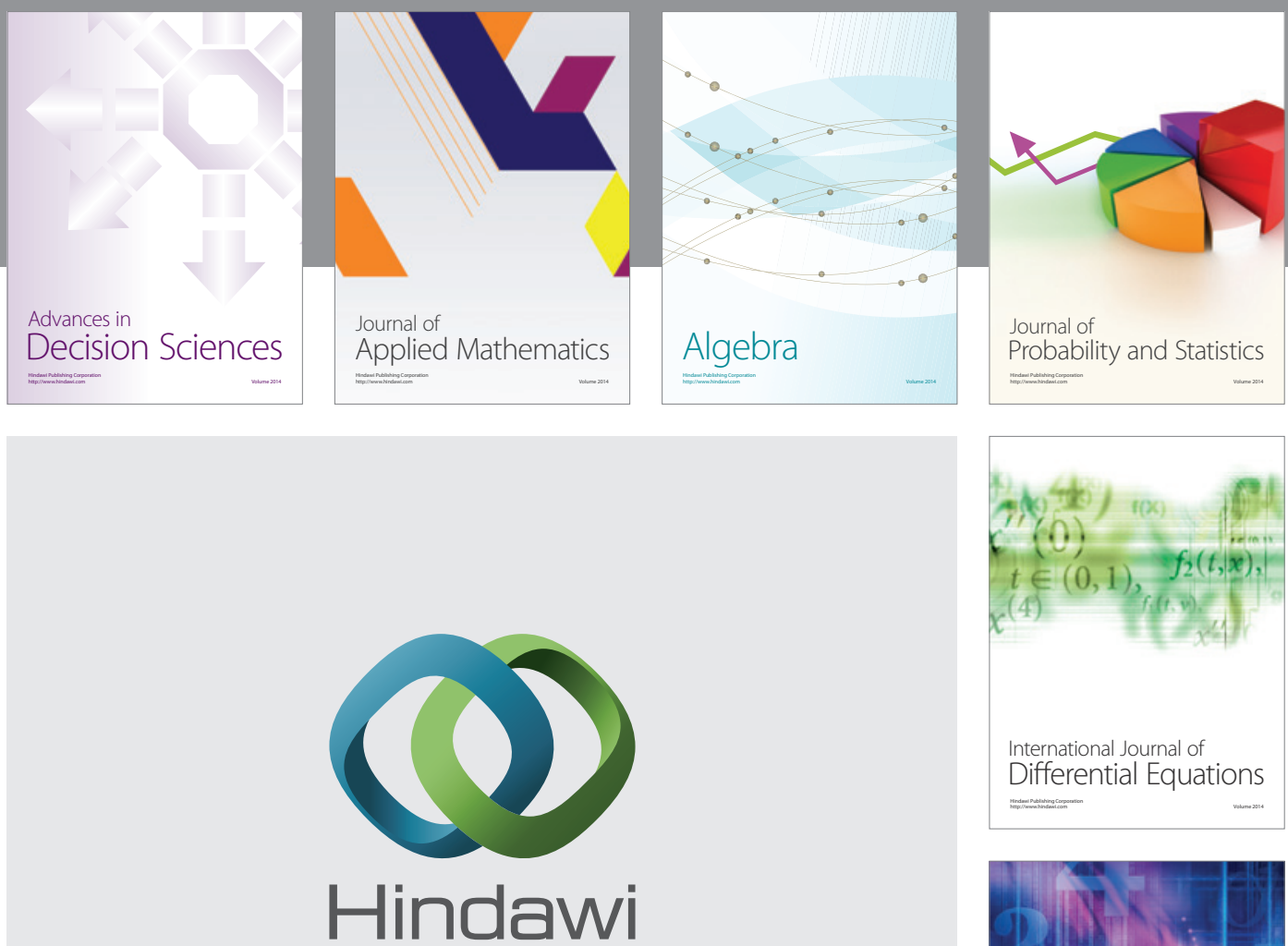

Submit your manuscripts at http://www.hindawi.com
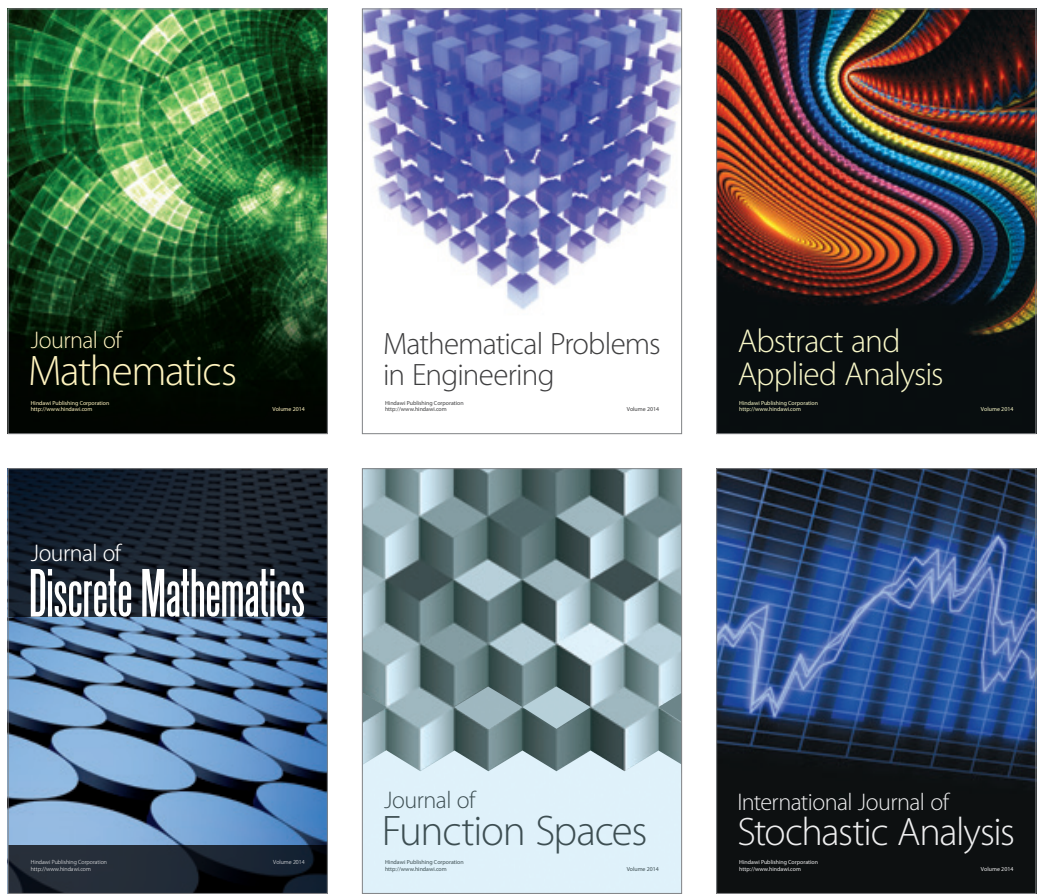

Journal of

Function Spaces

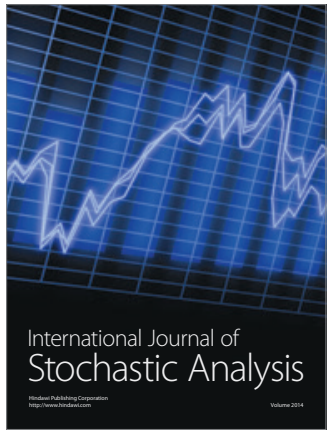

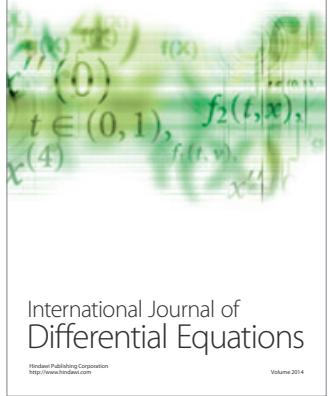
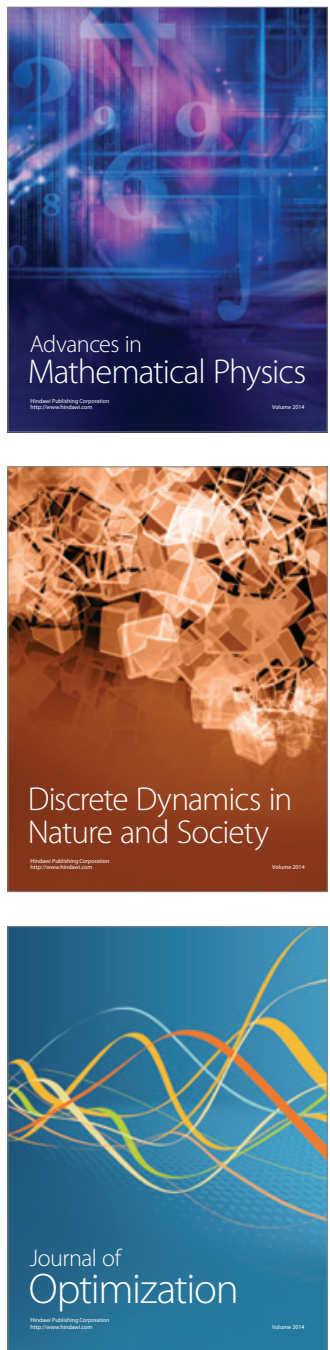